\title{
An Intertemporal International Asset Pricing Model: Theory and Empirical Evidence
}

\section{Jow-ran Chang}

Department of Quantitative Finance, National Tsing Hua University

e-mail: jrchang@mx.nthu.edu.tw

\section{Vihang Errunza}

Faculty of Management, McGill University, Montreal

e-mail:Vihang.errunza@mcgill.ca

\section{Ked Hogan}

Barclays Global Investors, San Francisco, CA, USA

e-mail:ked.hogan@barclaysglobal.com

\section{Mao-wei Hung}

College of Management, National Taiwan University

e-mail:hung@management.ntu.edu.tw

\begin{abstract}
We extend Campbell's (1993) model to develop an intertemporal international asset pricing model (IAPM). We show that the expected international asset return is determined by a weighted average of market risk, market hedging risk, exchange rate risk and exchange rate hedging risk. These weights sum up to one. Our model explicitly separates hedging against changes in the investment opportunity set from hedging against exchange rate changes as well as exchange rate risk from intertemporal hedging risk. A test of the conditional version of our intertemporal IAPM using a multivariate GARCH process supports the asset pricing model. We find that the exchange rate risk is important for pricing international equity returns and it is much more important than intertemporal hedging risk.
\end{abstract}

Keywords: international finance; asset pricing; currency risk; intertemporal.

JEL classification: $G 11, G 12, G 15$

\footnotetext{
We are grateful to Rene Stulz for many insightful comments. We thank Francesca Carrieri, Kris Jacobs, Darius Miller, Sergei Sarkissian and participants at the AFA 2003 meetings for helpful suggestions. We are grateful to an anonymous referee and the editor, John Doukas for many helpful comments. Errunza thanks the SSHRC for financial support. Correspondence: Vihang Errunza, Faculty of Management, McGill University, 1001 Sherbrooke St. West, Montreal, Quebec, Canada H3A 1G5.
} 


\section{Introduction}

Several theoretical international asset pricing models (IAPMs) focus on market risk and currency risk. Well known examples include Solnik (1974) and Adler and Dumas (1983). ${ }^{1}$ It is widely accepted that the intertemporal nature of the problem is important to consider (Merton, 1973; Stulz, 1981). ${ }^{2}$ Indeed, in the international setting, if investors hedge their exposure to anticipated variation in the investment opportunity set, both the market hedging risk and the currency hedging risk should be priced in addition to the market and currency risks. As a first step, Dumas and Solnik (1995) attempt to empirically evaluate the relative importance between exchange rate risk premia and intertemporal hedging premia. ${ }^{3}$ They state (p. 476):

We are not in a position to run a test with enough assets. But we can run a 'horse race' between the two types of models in order to determine which should be our first priority: the introduction of hedging risk premia as in the intertemporal, classic APM or the introduction of exchange rate risk premia as in the static, international APM.

Indeed, we are not aware of any existing intertemporal international asset pricing model that could be used to conduct a formal test. Hence, there are two primary goals of this paper. First, we develop a theoretical model that prices market hedging risk and exchange rate hedging risk in addition to market risk and exchange rate risk. This allows us to explicitly separate hedging against changes in the investment opportunity set from hedging against exchange rate changes as well as separate exchange rate risk from intertemporal hedging risk. ${ }^{4}$ Second, we test the asset pricing restrictions of our theoretical model, and assess the relative importance between exchange rate risk and hedging risk.

Campbell (1993) develops a domestic asset pricing model in which investors are assumed to be endowed with Kreps-Porteus utility and consumption is substituted out from the model. ${ }^{5}$ He demonstrates that the conditional covariance of any asset return with consumption growth can be written in terms of conditional covariances with the return on the market and revisions in expectations of future returns on the market. We extend Cambpell's (1993) model to an international framework in which the inflation rate is time-varying. We employ a recursive preference, which separates investors' attitudes towards risk from their willingness to substitute future consumption for present consumpdtion in pricing international assets. ${ }^{6}$ Our model prices

\footnotetext{
${ }^{1}$ Empirically, Harvey (1991) rejects the one (market) factor world IAPM, whereas De Santis and Gerard (1998), Solnik (1997), O'Brien and Dolde (2000) and Carrieri (2001) support currency risk as a priced factor based on a two (market and currency) factor IAPM.

${ }^{2}$ Based on a two (market and market hedging) factor CAPM, Chang and Hung (2000), and Hodrick et al. (2000) conclude that the intertemporal hedging risk is priced.

${ }^{3}$ De Santis and Gerard (1998) conduct an indirect test of the relevance of the intertemporal component of the model by including the information variables as explanatory variables.

${ }^{4}$ Our model can be viewed as a special case of the more general model of Stulz (1981).

${ }^{5}$ This avoids problems of measurement error and time-aggregation arising from aggregate consumption data.

${ }^{6}$ Past international asset pricing models assume investors maximise a time-additive, von Neumann-Morgenstern expected utility of life-time consumption function. This implies that the two distinct concepts of intertemporal substitution and risk aversion are characterised by the same parameter.
} 
exchange rate risk and exchange rate hedging risk in addition to market risk and market hedging risk. While the market hedging risk is the covariance of asset returns with news about the discounted value of all future market returns, the exchange rate hedging risk is the covariance of asset returns with news about the discounted value of all future currency returns.

Our main results can be summarised as follows. First, the expected international asset return can be expressed as a weighted average of consumption risk, inflation risk and market risk. Second, we use a log-linear approximation of the budget constraint to substitute out consumption to obtain an intertemporal international asset pricing model without consumption. We show that the expected international asset return is determined by a weighted average of market risk, market hedging risk, exchange rate risk and exchange rate hedging risk. Third, we estimate and test the conditional version of our intertemporal IAPM using a multivariate GARCH process. The evidence supports the international version of the intertemporal asset pricing model. Consistent with Dumas and Solnik (1995) and De Santis and Gerard (1998), we find that exchange rate risk is important for pricing international equity returns. Further, the exchange rate risk is much more important than intertemporal hedging risk.

The remainder of the paper is organised as follows. Section 2 derives the model of international asset pricing in which investors are endowed with homogeneous preferences. Section 3 constructs a model where investor's consumption preferences are nationally heterogeneous to derive a generalised intertemporal international asset pricing model. Section 4 discusses the econometric methodology. Data and empirical results are discussed in section 5. Section 6 provides a comparison of the contribution of exchange rate risk and intertemporal risk. Section 7 concludes the paper.

\section{Portfolio choice in an international setting}

In this section, we consider the problem of optimal consumption and portfolio allocation in a unified world capital market without taxes or transactions costs. Investors' preferences are assumed to be homogeneous and there is the same menu of assets for every investor in all countries. That is to say, everybody face the same consumption and investment opportunities and there exists a representative agent in the world. Therefore, we can formulate a economy where purchase power parity (PPP) holds. Section 3, we will disentangle this assumption to discuss an international asset pricing model under the deviation of PPP. Now, we consider a world of $\mathrm{L}+1$ countries and a set of $\mathrm{S}$ equity securities. All returns are measured in the $\mathrm{L}+1 \mathrm{st}$ country's currency (numeraire) in excess of the risk free rate. To facilitate discussion, we define the following terms:

$\pi_{t}$ : the price level expressed in the currency of country $\mathrm{L}+1$ at time $t$.

$R_{i, t}$ : the real return for security $i$ at time $t$.

$R_{i, t}^{N}$ : the nominal return for security $i$ at time $t$.

$C_{t}$ : the real consumption at time $t$.

$C_{t}^{N}$ : the nominal consumption at time $t$.

$R_{m, t}$ : the real return for market portfolio at time $t$.

$R_{m, t}^{N}$ : the nominal return for market portfolio at time $t$.

In this setup, the optimal solution can be obtained by specifying a real pricing kernel, $M_{t+1}$ : 


$$
1=E_{t}\left(R_{i, t+1} M_{t+1}\right),
$$

where $E_{t}$ is the expected value function conditional on the information available to the investor at time $t$.

Note that under perfect foresight the real return links the nominal return to inflation through the Fisher parity equation,

$$
R_{i, t+1}^{N} \frac{\pi_{t}}{\pi_{t+1}}=R_{i, t+1}
$$

we obtain the pricing formula under time-varying inflation rate,

$$
1=E_{t}\left(R_{i, t+1}^{N} \frac{\pi_{t}}{\pi_{t+1}} M_{t+1}\right) .
$$

Furthermore, investors are assumed to have a Kreps-Porteus utility. Following Epstein and Zin (1989), it can be shown that the pricing kernel has the following form:

$$
M_{t+1}=\beta\left\{\left(\frac{C_{t+1}}{C_{t}}\right)^{-1 / \sigma}\right\}^{\theta}\left\{R_{m, t+1}\right\}^{\theta-1},
$$

where the parameter $\beta$ is the agent's subjective time discount factor, $\theta$ is defined as $\theta=(1-\gamma) /[1-(1 / \sigma)]$, and $\gamma$ can be interpreted as the Arrow-Pratt coefficient of relative risk aversion. It can also be shown that $\sigma$ measures the elasticity of intertemporal substitution. For instance, if the agent's coefficient of relative risk aversion, $\gamma$, is greater (smaller) than the reciprocal of his elasticity of intertemporal substitution, $1 / \sigma$, then he prefers early (late) resolution of uncertainty. If $\gamma$ is equal to $1 / \sigma$, the agent's utility becomes an isoelastic von Neumann-Morgenstern utility and he is indifferent to the timing of the resolution of uncertainty.

Plugging equation (4) into equation (3), we obtain

$$
1=E_{t}\left[R_{i, t+1}^{N} \frac{\pi_{t}}{\pi_{t+1}} \beta\left\{\left[\frac{C_{t+1}^{N} / \pi_{t+1}}{C_{t}^{N} / \pi_{t}}\right]^{-1 / \sigma}\right\}^{\theta}\left\{R_{m, t+1}^{N} \frac{\pi_{t}}{\pi_{t+1}}\right\}^{\theta-1}\right] .
$$

Equation (5) is the basic pricing formula. Based on equation (5), we will follow Campbell (1993) to substitute consumption out of the pricing formula.

When $\gamma=1 / \sigma$, the Euler equations of the time additive expected utility model are also obtained under random inflation assumption:

$$
1=E_{t}\left\{R_{i, t+1}^{N} \frac{\pi_{t}}{\pi_{t+1}} \beta\left[\frac{C_{t+1}^{N} / \pi_{t+1}}{C_{t}^{N} / \pi_{t}}\right]^{-1 / \sigma}\right\}
$$

Another special case is the logarithmic risk preference where $\gamma=1 / \sigma=1$. Then, the Euler equations under fixed inflation are same as the Euler equations under random inflation and can be written in two algebraically identical functional forms:

$$
1=E_{t}\left\{R_{i, t+1}^{N} \beta\left[\frac{C_{t+1}^{N}}{C_{t}^{N}}\right]^{-1}\right\}
$$

or 


$$
1=E_{t}\left\{R_{i, t+1}^{N} / R_{m, t+1}^{N}\right\}
$$

In this case, the parameter $\sigma$ governing intertemporal substitutability can not be identified from these equations. Hence, under logarithmic risk preferences there is no difference between Euler equations of the non-expected utility model and the expected utility model.

If we assume that asset prices and consumption are jointly lognormal or alternatively if we assume that asset prices and consumption are conditional homoskedastic and use a second order Taylor expansion, the log-version of the real Euler equation (5) can be represented as:

$$
\begin{aligned}
0= & \theta \log \beta-(\theta / \sigma) \underset{t}{E} \Delta c_{t+1}+(\theta-1) \underset{t}{E} r_{m, t+1}+\underset{t}{E} r_{i, t+1}+\theta((1 / \sigma)-1) \underset{t}{E} \Delta \pi_{t+1} \\
& +\frac{1}{2}\left[(\theta / \sigma)^{2} V_{c c}+(\theta-1)^{2} V_{m m}+V_{i i}-2(\theta / \sigma)(\theta-1) V_{c m}-2(\theta / \sigma) V_{c i}\right. \\
& \left.+2(\theta-1) V_{i m}\right]+\frac{1}{2}\left\{\left[(\theta((1 / \sigma)-1)]^{2} V_{\pi \pi}-2 \theta^{2}(1 / \sigma)((1 / \sigma)-1) V_{\pi c}\right.\right. \\
& \left.+2 \theta(\theta-1)((1 / \sigma)-1) V_{\pi m}+2 \theta((1 / \sigma)-1) V_{\pi i}\right\}
\end{aligned}
$$

where lowercase letters are used for logs and $V_{c c}$ denotes $\operatorname{var}_{t}\left(c_{t+1}\right), V_{j j}$ denotes $\operatorname{var}_{t}$ $\left(r_{j, t+1}\right) \forall j=i, m, V_{c j}$ denotes $\operatorname{cov}_{t}\left(c_{t+1}, r_{j, t+1}\right) \forall j=i, m, V_{i m} \operatorname{denotes} \operatorname{cov}_{t}\left(r_{i, t+1}, r_{m, t+1}\right)$, $V_{i \pi}=\operatorname{cov}_{t}\left(r_{i, t+1}, r_{\pi, t+1}\right)$, and $r_{\pi, t+1}=d \ln \left(\pi_{t+1}\right)=\frac{d \pi_{t+1}}{\pi_{t+1}}$. In equation (9), we do not assume that asset prices and consumption are conditional homoskedastic. In other words, the conditional second moments in equation (9) are time-varying.

Replacing the asset $i$ by market portfolio and rearranging, we obtain the relationship among expected consumption growth and the expected return on the market portfolio and expected price level growth:

$$
\begin{aligned}
\underset{t}{E \Delta c_{t+1}=} & \sigma \log \beta+\frac{1}{2}\left[(\theta / \sigma) V_{c c}+\theta \sigma V_{m m}+2(1-\sigma) \theta((1 / \sigma)-1) V_{\pi \pi}\right] \\
& -\frac{1}{2}\left[2 \theta V_{c m}+2 \theta((1 / \sigma)-1) V_{\pi c}-2 \theta(1-\sigma) V_{\pi m}\right] \\
& +\sigma \underset{t}{E} r_{m, t+1}+(1-\sigma) \underset{t}{E} r_{\pi, t+1} \\
= & \theta \log \beta+\frac{1}{2}(\theta / \sigma) \operatorname{var}\left[\Delta c_{t+1}-\sigma r_{m, t+!}+(1-\sigma) \Delta \pi_{t+!}\right]+\sigma \underset{t}{E} r_{m, t+1} \\
& +(1-\sigma) \underset{t}{E} r_{\pi, t+1}
\end{aligned}
$$

As has been noted, the second term in equation (10) is not a constant now. Equation (10) indicates that after adjusting the first and second term in equation (10), consumption growth is linearly related to the expected market return and expected inflation. In addition, the coefficients of these two variables add up to one.

When we subtract the risk free version of (9) from the general version, we obtain:

$$
\mathrm{e}^{\left.E_{t} r_{i, t+1}-r_{f, t+1}=-\frac{V_{i i}}{2}+(\theta / \sigma) V_{i c}+(\theta-(\theta / \sigma)) V_{i \pi}+(1-\theta) V_{i m}\right)}
$$

where $r_{f, t+1}$ is a log riskless nominal interest rate. If inflation is fixed or known ex ante, this result is the same as Campbell (1993). Equation (11) shows that the expected excess $\log$ return on an asset is a linear combination of its own variance, which is produced by Jensen's inequality, and by a weighted average of three covariances. The 
weights on the consumption, inflation and market are $\theta / \sigma,(\theta-(\theta / \sigma))$ and $(1-\theta)$, respectively which sum up to 1 . In Campbell (1993), $V_{i \pi}$ is equal zero and the weights on consumption and market are $\theta / \sigma$ and $(1-\theta)$ which does not sum up to 1 . This is one of the most important differences between Campbell's model and our random inflation model.

If the objective function is a time-separable power utility function, a real functional form of the loglinear version consumption CAPM pricing formula can be obtained:

$$
\underset{t}{E} r_{i, t+1}-r_{f, t+1}=-\frac{V_{i i}}{2}+(1 / \sigma) V_{i c}+(1-(1 / \sigma)) V_{i \pi}
$$

The weights on the consumption and inflation are $1 / \sigma$ and $(1-(1 / \sigma))$, respectively that also sum up to one. However, when the coefficient of relative risk aversion $\gamma=1$, then $\theta=0$, and the model can be collapsed into the real functional form of the loglinear static CAPM which is the same as the nominal structure of the loglinear static CAPM.

The representative agent in the world can invest his wealth in $Q(=\mathrm{L}+\mathrm{S})$ assets which comprise $\mathrm{L}$ currencies and $\mathrm{S}$ equities. Currencies may be taken to be the nominal bank deposits denominated in the non-numeraire currencies. The representative agent's dynamic budget constraint under time-varying inflation can be written as:

$$
\frac{W_{t+1}}{\pi_{t+1}}=R_{m, t+1}^{N} \frac{\pi_{t}}{\pi_{t+1}}\left(\frac{W_{t}}{\pi_{t}}-\frac{C_{t}^{N}}{\pi_{t}}\right)
$$

where $W_{t+1}$ is the investor's nominal wealth at time $\mathrm{t}+1$. The budget constraint in equation (13) is nonlinear because of the interaction between subtraction and multiplication.

Following Campbell (1993), we linearise the budget constraint by dividing equation (13) by $W_{t}$, taking the log, and then using a first-order Taylor approximation around the mean $\log$ consumption/wealth ratio $\log (C / W)$.

$$
\begin{aligned}
c_{t+1}-\underset{t}{E} c_{t+1}= & r_{m, t+1}-\underset{t}{E} r_{m, t+1}+(1-\sigma)(\underset{t+1}{E}-\underset{t}{E}) \sum_{j=1}^{\infty} \beta^{j} r_{m, t+1+j} \\
& -(1-\sigma)(\underset{t+1}{E}-\underset{t}{E}) \sum_{j=1}^{\infty} \beta^{j} r_{\pi, t+1+j} \\
& -\frac{1}{2}(\theta / \sigma) \sum_{j={ }^{\prime} 1}^{\infty} \rho^{j}\left\{\operatorname{Var}_{t+1}\left[\Delta c_{t+1+j}-\sigma r_{m, t+1+j}+(1-\sigma) \Delta \pi_{t+1+j}\right]\right. \\
& -\operatorname{Var}_{t}\left[\Delta c_{t+1+j}-\sigma r_{m, t+1+j}+(1-\sigma) \Delta \pi_{t+1+j}\right]
\end{aligned}
$$

Equation (14) implies that unexpected consumption may come from four sources. The first source is the unexpected return on invested wealth today. The second source is the expected future nominal returns that depend on the magnitude of $\sigma$. When $\sigma$ is less than one, an increase (or decrease) in the expected future nominal return increases (or decreases) the unexpected consumption. Conversely, when $\sigma$ is greater than one, an increase (or decrease) in the expected future nominal return decreases (or increases) the unexpected consumption. The third source is the inflation rate that also depends on the magnitude of $\sigma$. When $\sigma$ is less than one, an increase (or decrease) in the inflation decreases (or increases) the unexpected consumption. Conversely, when $\sigma$ is 
greater than one, an increase (or decrease) in the inflation increases (or decreases) the unexpected consumption.

The last term in equation (14) is related to the conditional variance of market return. Note that in the original model of Campbell (1993), all variances and covariances of log asset and consumption are constant through time, and the last term in equation (14) is constant. Campbell (1993) notes several ways in which consumption can be subsitituted out of the model with changing variances. ${ }^{7}$ One of them is to set the elasticity of intertemporal substitution $\sigma=1$, then $\theta$ is infinite, and the conditional variance of (14) must be zero. In this case, pricing formula can be derived in an environment of conditional heteroskedasticity. However, when we test the model empirically in the next section, we assume that the conditional variance of market return follows a GARCH process which is uncorrelated with any asset returns. ${ }^{8}$ Hence, based on equation (14), the conditional covariance of any asset return with consumption can be rewritten in terms of the covariances with the return on the market and revisions in expectations of future return on the market and inflation:

$$
\operatorname{cov}_{t}\left(r_{i, t+1}, \Delta c_{t+1}\right) \equiv V_{i c}=V_{i m}+(1-\sigma) V_{i h}-(1-\sigma) V_{i h \pi},
$$

$$
\text { where, } \begin{aligned}
V_{i h} & =\operatorname{cov}_{t}\left(r_{i, t+1},(\underset{t+1}{E}-\underset{t}{E}) \sum_{j=1}^{\infty} \beta^{j} r_{m, t+1+j}\right) \\
V_{i h \pi} & =\operatorname{cov}_{t}\left(r_{i, t+1},(\underset{t+1}{E}-\underset{t}{E}) \sum_{j=1}^{\infty} \beta^{j} r_{\pi, t+1+j}\right)
\end{aligned}
$$

Substituting equation (15) into equation (11), we obtain an asseat pricing model with random price, which is not related to consumption:

$$
\underset{t}{E} r_{i, t+1}-r_{f, t+1}=-\frac{V_{i i}}{2}+\gamma V_{i m}+(\gamma-1) V_{i h}+(1-\gamma) V_{i \pi}+(1-\gamma) V_{i h \pi}
$$

The only preference parameter that enters equation (16) is the coefficient of relative risk aversion $\gamma$. The elasticity of intertemporal substitution $\sigma$ has disappeared from this asset pricing model. Equation (16) states that the expected excess log return of an asset, adjusted for a Jensen's inequality effect, is a weighted average of four covariances. The covariances are with the return on the market portfolio, with news about future returns on invested wealth, with the return from inflation, and with news about future inflation.

\section{The intertemporal international asset pricing model under PPP deviation}

In this section, we consider the problem of optimal consumption and portfolio allocation in a unified world capital market where investors' preferences are assumed to be nationally heterogeneous, but there is the same menu of assets for every investor in all countries. That is to say, there does not exist a representative agent in the world. In this paper, we assume that PPP still hold in each domestic country and there is a

\footnotetext{
${ }^{7}$ Relaxing this assumption has no effect on the log-linearisation of the budget constraint and the formulation of the intertemporal optimisation problem.

${ }^{8}$ Restoy (1991) also extends Campbell (1993) to discuss the case in which the variance of market return follows a GARCH process.
} 
representative agent in each domestic country. Therefore, we can first deal with a representative agent in each country like we do in the section 2, and then aggregate across countries to obtain a generalised international asset pricing model. We now turn to the problem of aggregation directly. It is true that different investors may use different sets of information and models to forecast future market returns and inflation. To obtain the aggregation results, we first add the superscript $l$ to equation (16) to indicate the optimal condition for investor $l$ who is a representative agent in the country $l$ :

$$
\underset{t}{E} r_{i, t+1}-r_{f, t+1}=-\frac{V_{i i}}{2}+\gamma^{l} V_{i m}^{l}+\left(\gamma^{l}-1\right) V_{i h}^{l}+\left(1-\gamma^{l}\right) V_{i \pi}^{l}+\left(1-\gamma^{l}\right) V_{i h \pi}^{l}
$$

Next, we multiply equation (17) by $\eta^{l}$, where $\eta^{l}=1 / \gamma^{l}$ and then take an average over all investors, where the weights are the investors' relative wealth. ${ }^{9}$

$$
\begin{aligned}
\underset{t}{E} r_{i, t+1}-r_{f, t+1}= & -\frac{V_{i i}}{2}+\frac{1}{\eta^{m}} V_{i m}^{m}+\left(\frac{1}{\eta^{m}}-1\right) \sum_{l} \omega^{l} V_{i h}^{l} \\
& +\left(1-\frac{1}{\eta^{m}}\right) \sum_{l} \omega^{l} V_{i \pi}^{l}+\left(1-\frac{1}{\eta^{m}}\right) \sum_{l} \omega^{l} V_{i h \pi}^{l}
\end{aligned}
$$

where, $\eta^{m}=\left(\sum_{l} W^{l} \eta^{l}\right) /\left(\sum_{l} W^{l}\right)$ and $\omega^{l}=\frac{\left(1-\gamma^{l}\right) W^{l}}{\sum_{l}\left(1-\gamma^{l}\right) W^{l}}$.

The drawback is that the third, fourth, and fifth terms of (18) are unobservable. In the international setting, they contain the covariances of security $i$ with the heterogeneous investors' rate of market return forecasting, rate of inflation, and inflation forecasting. They are weighted by their wealth and by one minus their relative risk aversion. Because it is impossible to measure each individual's relative risk aversion, we cannot use the wealth and relative risk aversion weighted average rate of market return forecasting, rate of inflation, or inflation forecasting. Since all individuals of the same country use the same deflator and we use the national wealth weighted average relative risk aversion instead of the individual ones, we have a sum of one term per each country.

Several interesting and intuitive results emerge. First, the international asset risk premium adjusted for one-half its own variance is related to its covariances with: (a) the market portfolio, (b) the aggregate of innovation in discounted expected future market returns from different investors across countries, (c) the aggregate of inflation from different countries, and (d) the aggregate of innovation in inflation of different investors, discounted using values for expected future inflation across different countries. The weights are $1 / \eta^{m}, 1 / \eta^{m}-1,1-1 / \eta^{m}, 1-1 / \eta^{m}$, respectively that sum to one. ${ }^{10}$ Second, the international asset is priced without referring to its covariance with consumption growth. Third, because consumption has been substituted out, the coefficient of risk tolerance, $\eta_{m}$, is the only preference parameter that enters the asset pricing model - equation (18).

\footnotetext{
${ }^{9}$ We follow Adler and Dumas (1983) to deal with the intrinsic problem of aggregation in international asset pricing.

${ }^{10}$ The market hedging risk is a weighted average of the market portfolio for investors from different countries. This is different from the domestic counterpart of Campbell (1993).
} 
If we are willing to make further simplifying assumptions, we can obtain a more compact result. Specifically, if investors have identical current and future market portfolio expected returns, we can take an average over all investors, where the weights are their relative wealth, and thus obtain a simple version of the intertemporal international asset pricing model:

$$
\begin{aligned}
\underset{t}{\operatorname{Er}} r_{i, t+1}-r_{f, t+1}= & -\frac{V_{i i}}{2}+\gamma^{m} V_{i m}+\left(\gamma^{m}-1\right) V_{i h} \\
& +\left(1-\gamma^{m}\right) \sum_{l} \omega^{l} V_{i \pi}^{l}+\left(1-\gamma^{m}\right) \sum_{l} \omega^{l} V_{i h \pi}^{l}
\end{aligned}
$$

where, $\gamma^{m}=\left(\sum_{l} W^{l} \gamma^{l}\right) /\left(\sum_{l} W^{l}\right)$ and $\omega^{l}=\frac{\left(1-\gamma^{l}\right) W^{l}}{\sum_{l}\left(1-\gamma^{l}\right) W^{l}}$.

In our model, inflation rate measured in currency of country $L+1$ contains inflation rate in domestic and exchange rate between domestic currency and the currency of country $L+1$. Therefore, we should separate our inflation rate measured in currency of country L +1 to country l's inflation rate and percentage change in exchange rate. We assume that $\pi^{L+1}$ is country l's price level measured in currency of country $\mathrm{L}+1, \pi^{l}$ is country l's price level measured in currency of country $l$, and $S$ is currency $\mathrm{L}+1$ price of currency $l, \mathrm{~S} \$(\mathrm{~L}+1) / \$(l)$.

$$
\begin{aligned}
\frac{\pi_{t+1}^{L+1}}{\pi_{t}^{L+1}} & =\frac{\pi_{t+1}^{l}}{\pi_{t}^{l}} * \frac{S_{t+1}}{S_{t}} \\
\Delta \ln \left(\pi_{t+1}^{L+1}\right) & =\Delta \ln \left(\pi_{t+1}^{l}\right)+\Delta \ln \left(S_{t+1}\right) \\
r_{\pi^{L+1}, t+1} & =r_{\pi^{l}, t+1}+r_{e, t+1} \\
V_{i, \pi}^{l} & =V_{i, \pi^{l}}^{l}+V_{i, e}^{l}
\end{aligned}
$$

Therefore, inflation risk includes inflation risk measured in domestic currency and exchange rate risk. If domestic inflation is a stable variable, the only random component in $\pi$ is the relative change in the exchange rate between the numeraire currency and the investor's home currency. Then, $V_{i \pi}^{l}$ is a pure measure of the exposure of asset $i$ to the exchange rate risk and $V_{i h \pi}^{l}$ is a measure of the exposure of asset $i$ to hedge against the exchange rate risk of the country in which investor $l$ resides.

Equation (19) also states that the exchange rate risk is different from the hedging risk. Indeed, if $V_{i h}$ and $V_{i \pi}^{l}$ are significantly large, then their contribution to expected return depends on whether $\gamma^{m}$ is different from one. This may be the reason why Dumas and Solnik (1995) argue that exchange rate risk premium may be equivalent to intertemporal risk premium. Their conjecture is, however, based on an empirical 'horse race' test between an international model and an intertemporal model.

\section{Empirical methodology}

In this section, we propose an empirical methodology to examine the theoretical model. First, we adopt the approach of Campbell (1991) to construct a state variable system to estimate the market hedging portfolio and currency hedging portfolio. Next, we connect the international intertemproal asset pricing and a dynamic covariance system to an econometric model. Finally, we use these two systems as the benchmark model to estimate all the unknown parameters. 


\section{A. Vector auto-regressive model}

We adopt the vector auto-regressive (VAR) approach of Campbell (1991) and construct a state variable system to estimate the market hedging portfolio and the currency hedging portfolio. We assume that the market index return, $r_{m}$, is the first element of a $K$-element state variable vector $z_{t}$ and the currency deposit return, $r_{e}^{l}$, is the $l+1$ st element, $l=1,2, \ldots, L$. The other elements of $z_{t}$ are known to the market at the end of period $t$ and are related to the forecasting of future market returns and currency deposit returns. In addition, we assume that all the variables $z_{t}$ are demeaned and that the vector $z_{t}$ follows a first order VAR.

$$
z_{t+1}=\Psi z_{t}+u_{t+1}
$$

where $\Psi$ is a $N \times N$ companion matrix of the VAR. The representation of the VAR as a first-order is not restrictive because a higher-order VAR can always be stacked into first-order companion form as discussed by Schwarz (1978). Then we can use the first order VAR to generate simple multi-period forecasts of future returns as,

$$
\underset{t}{E} z_{t+1+i}=\Psi^{i+1} z_{t}
$$

Define a $K$-element constant vector $e 1$ whose first element is one and the other elements are all zero. Then, $r_{m, t}=e 1^{\prime} z_{t}$ and $r_{m, t+1}-E r_{m, t+1}=e 1^{\prime} u_{t+1}$. Define another $K$-element constant vector $e l$ whose $l+1$ st element is one and other elements are all zero. Then, $r_{e, t}^{l}=e l^{\prime} z_{t}$ and $r_{e, t+1}^{l}-E r_{e, t+1}^{l}=e l^{\prime} u_{t+1}$.

It follows that the discounted sum of forecast revisions in market returns is,

$$
\begin{aligned}
(\underset{t+1}{E}-\underset{t}{E}) \sum_{j=1}^{\infty} \beta^{j} r_{m, t+1+j} & =e 1^{\prime} \sum_{j=1}^{\infty} \beta^{i} \Psi^{j} u_{t+1} \\
& =e 1^{\prime} \beta \Psi(\mathbf{I}-\beta \Psi)^{-1} u_{t+1} \\
& =\theta_{h}^{\prime} u_{t+1},
\end{aligned}
$$

where, $\theta_{h}^{\prime}$ is defined as $e 1^{\prime} \beta \Psi(\mathbf{I}-\beta \Psi)^{-1}$ which measures the importance of each state variable in forecasting future returns on the market.

Similarly, the discounted sum of forecast revisions in currency deposit returns is,

$$
\begin{aligned}
(\underset{t+1}{E}-\underset{t}{E}) \sum_{j=1}^{\infty} \beta^{j} r_{e, t+1+j}^{l} & =e l^{\prime} \sum_{j=1}^{\infty} \beta^{i} \Psi^{j} u_{t+1} \\
& =e l^{\prime} \beta \Psi(\mathbf{I}-\beta \Psi)^{-1} u_{t+1} \\
& =\theta^{\prime l^{\prime}} u_{t+1},
\end{aligned}
$$

where, $\theta_{e}^{l^{\prime}}$ is defined as $e l^{\prime} \beta \Psi(\mathbf{I}-\beta \Psi)^{-1}$ which measures the importance of each state variable in forecasting future returns on the currency deposit.

Thus, equation (18) can now be written as,

$$
\begin{aligned}
E r_{i, t+1}-r_{f, t+1}= & -\frac{V_{i i}}{2}+\gamma V_{i m}+(1-\gamma) \sum_{l=1}^{L} \omega^{l} V_{i e}^{l}+\sum_{k=1}^{K}\left[(\gamma-1) \theta_{h, k}\right. \\
& \left.+(1-\gamma) \sum_{l=1}^{L} \omega^{l} \theta_{e, k}^{l}\right] V_{i k}
\end{aligned}
$$


We define $V_{i k} \equiv \operatorname{Var}_{t}\left(r_{i, t+1}, u_{k, t+1}\right)$, where $u_{k, t+1}$ is the $k$ th element of $u_{t+1}$. Equation (24) implies that the expected $\log$ excess return on asset $i$, adjusted for the effect of Jensen's inequality, is linear in the covariance of the return with the $\mathrm{K}$ factors. The set of restrictions on the risk prices of the factor is the most important contribution of the intertemporal optimisation problem in the international asset pricing model. For example, the first factor, the innovation in the market return, has a risk price of $\gamma+(\gamma-1) \theta_{h, 1}+(1-\gamma) \sum \omega^{l} \theta_{l, 1}^{l}$. Thus, the international intertemporal model suggests that priced factors should not be found neither by selecting important macroeconomic variables, nor by running a factor analysis on the covariance matrix of returns.

\section{B. Econometric specification}

Equation (19) appears to be the natural relation to use in an empirical investigation of the intertemporal IAPM because it takes into account the investor's use of newly acquired information in creating a portfolio, thus taking into account his hedging strategy. The model requires equation (19) to hold for every asset including the market portfolio, market hedging portfolio, currency portfolio and currency hedging portfolio. Therefore, we assume that each asset return satisfies the following system of pricing restrictions:

$$
\begin{aligned}
& \underset{t}{E} r_{1, t+1}-r_{f, t+1}=-\frac{V_{11}}{2}+\gamma V_{1 m}+(\gamma-1) V_{1 h}+(1-\gamma) \sum_{l=1}^{L} \omega^{l} V_{1 e}^{l}+(1-\gamma) \sum_{l=1}^{L} \omega^{l} V_{1 e h}^{l}
\end{aligned}
$$

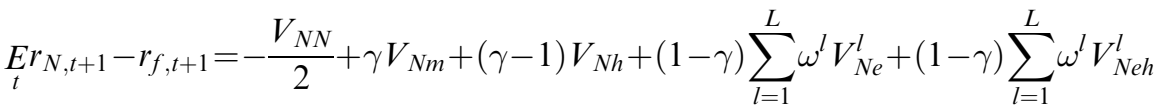

where, we replace $V_{i \pi}$ and $V_{i \pi h}$ in equation (19) with $V_{i e}$ and $V_{i e h}$ because the empirical evidence shows that for our sample countries, the fluctuations in domestic inflation are almost negligible relative to exchange rate changes. ${ }^{11}$

Let $r_{t}$ denote the $N \times 1$ time series vector which includes $N$ risky assets, $r_{i} \forall i=1, \ldots, N$. In matrix notation, equation (25) and equation (20) can be re-expressed in terms of random log excess return as,

$$
\begin{aligned}
{\left[\begin{array}{c}
z_{t} \\
r_{t}-r_{f, t} \cdot i
\end{array}\right] } & =\left[\begin{array}{l}
\Phi z_{t-1} \\
-\frac{1}{2} h_{d, t}+\gamma h_{m, t}+(\gamma-1) h_{h, t}+(1-\gamma) h_{e, t}+(1-\gamma) h_{e h, t}
\end{array}\right]+\left[\begin{array}{l}
u_{t} \\
\xi_{t}
\end{array}\right] \\
\varepsilon_{t} & =\left[\begin{array}{l}
u_{t} \\
\xi_{t}
\end{array}\right] \mid I_{t-1} \sim N\left(0, H_{t}\right), \\
H_{t} & :(K+N) \times(K+N)=\left[\begin{array}{ll}
H_{K \times K}^{11} & H_{K \times N}^{12} \\
H_{N \times K}^{21} & H_{N \times N}^{22}
\end{array}\right]
\end{aligned}
$$

where, $i$ is an $N \times 1$ vector of one, $H_{t}$ is the conditional covariance matrix of asset returns, $h_{d, t}$ is the diagonal element of $H_{N \times N}^{22}$ which denotes the conditional variance

\footnotetext{
${ }^{11}$ Note that DeSantis and Gerard (1998) make the same simplification. Our dataset is also similar to theirs. 
of each risk asset, $h_{m}, t$ is the 1 st column of $H_{N \times K}^{21}$ which denotes the conditional covariance of each asset with the market portfolio, $h_{h, t}=\sum_{k=1}^{K} \theta_{h, k} h_{k, t}$ denotes the conditional covariance of each asset with the market hedging portfolio, $h_{e, t}=\sum_{l=1}^{L} \omega^{l} h_{l+1, t}$ denotes the conditional covariance of each asset with the currency portfolio, $h_{e h, t}=\sum_{l=1}^{L} \omega^{l} \sum_{k=1}^{K} \theta_{e, k}^{l} h_{k, t}$ denotes the conditional covariance of each asset with the currency hedging portfolio, $h_{k, t}$ is the $k$ th column of $H_{N \times K}^{21}$ and $h_{l+1, t}$ is the $l+1$ st column of $H_{N \times K}^{21}$.

Three tests of asset pricing restrictions as special cases of equation (26) are implemented. First, we test the validity of the conditional CAPM that implies that $\gamma$ must be significantly different from zero. The null hypothesis of $\gamma=0$ is tested against the alternative hypothesis $\gamma \neq 0$. Second, the test of market hedging risk, exchange rate risk and exchange rate hedging risk as an important factor in the asset pricing model is implemented. This test implies that $\gamma$ is not equal to one in equation (26). Otherwise, risk premia of assets are determined only by the covariance with the market portfolio. As discussed in the theoretical model of Section III, if we only test the price of market hedging risk, $V_{i h}$, and currency risk, $V_{i e}$, we can find that the two risk values will be significant or insignificant simultaneously because they all depend on whether or not relative risk aversion, $\gamma$, is different from one. Hence, we ultimately want to know which risk is most important in terms of scale.

Equation (26) follows directly from the system of the intertemporal IAPM. To implement the tests of the above hypotheses, the dynamics of the variance-covariance structure in equation (26) must be specified. A multivariate GARCH process based on the work of Ding and Engle (1994) is used to obtain a testable version of the model.

For simplicity, we assume that the innovation vector $\varepsilon_{t}$ follows a $\operatorname{GARCH}(1,1)$ process. The time-varying conditional covariance matrix therefore can be parameterised as,

$$
H_{t}=\Gamma+\mathbf{a} \varepsilon_{t-1} \varepsilon_{t-1}^{\prime} \mathbf{a}^{\prime}+\mathbf{b} H_{t-1} \mathbf{b}^{\prime},
$$

where, $\Gamma$, $\mathbf{a}$, and $\mathbf{b}$ denote $(N+K) \times(N+K)$ matrices of parameters. It is difficult to estimate the model due to the large number of unknown parameters. In practice, it is necessary to further restrict the specification for $H_{t}$ to obtain a numerically tractable formulation. One useful special case is to assume that both $\mathbf{a}$ and $\mathbf{b}$ are restricted to be diagonal matrices. In such a parameterisation, the conditional covariance between $\varepsilon_{i, t}$ and $\varepsilon_{j, t}$ depends only on past values of $\varepsilon_{i, t-1} \cdot \varepsilon_{j, t-1}$, and not on the products or squares of other residuals. Therefore, equation (27) can be written in a simple form:

$$
H_{t}=\Gamma+\alpha \alpha^{\prime} * \varepsilon_{t-1} \varepsilon_{t-1}^{\prime}+\beta \beta^{\prime} * H_{t-1},
$$

where, $\alpha, \beta$ are $N \times 1$ vector which includes the diagonal elements of $\mathbf{a}$ and $\mathbf{b}$, respectively, and the symbol * denotes the Hadamard (element by element) matrix product. However, the diagonal assumption is still too difficult to estimate, unless we can again reduce the number of unknown parameters. To this end, we assume that the $\varepsilon_{t}$ process is covariance stationary following Ding and Engle (1994). Consider the following system of equations,

$$
\left[\begin{array}{c}
z_{t} \\
r_{t}
\end{array}\right]=E_{t-1}\left[\begin{array}{c}
z_{t} \\
r_{t}
\end{array}\right]+\varepsilon_{t} \quad \varepsilon_{t} \mid I_{t-1} \sim N\left(0, H_{t}\right)
$$

If the $\varepsilon_{t}$ process is covariance stationary, its unconditional variance-covariance matrix is equal to, 


$$
H_{0}=\Gamma *\left(i i^{\prime}-\alpha \alpha^{\prime}-\beta \beta^{\prime}\right)^{-1} .
$$

Then, equation (28) is replaced by,

$$
H_{t}=H_{0} *\left(i i^{\prime}-\alpha \alpha^{\prime}-\beta \beta^{\prime}\right)+\alpha \alpha^{\prime} * \varepsilon_{t-1} \varepsilon_{t-1}^{\prime}+\beta \beta^{\prime} * H_{t-1} .
$$

In a covariance stationary and diagonal construction with $(N+K)$ assets, the number of unknown parameters in the conditional variance equation is reduced to $2(N+K)$. The unconditional variance-covariance matrix, $H_{0}$, is not directly observable. Here we set it equal to the sample covariance matrix of the return.

We use equations (26) and (31) as the benchmark model. Let $\psi$ be the unknown parameters in the model. Then, under the assumption of conditional normality, the log-likelihood function can be written as,

$$
\ln L(\psi)=-\frac{T N}{2} \ln 2 \pi-\frac{1}{2} \sum_{t=1}^{T} \ln \left|H_{t}(\psi)\right|-\frac{1}{2} \sum_{t=1}^{T} \varepsilon_{t}(\psi)^{\prime} H_{t}(\psi)^{-1} \varepsilon_{t}(\psi) .
$$

We estimate this model and compute all tests using the Quasi-Maximum Likelihood Estimation (QMLE) approach proposed by Bollerslev and Wooldridge (1992). QMLE estimation provides consistent estimates of the parameters. The standard errors for the estimated coefficients that are calculated under the normal assumption need not be correct if the true data generating process is non-normal. Hence, we use the robust Lagrange Multiplier (LM) test to test the alternative model.

\section{Data and empirical results}

We use monthly dollar denominated index returns for the USA, the UK, Germany, Japan, and the world portfolio as reported by Morgan Stanley Capital International (MSCI) to investigate the proposed international asset pricing model. The sample period is from January 1980 through December 1997. We also use Eurocurrency rates offered in the interbank market in London for one-month deposits in US dollars, UK pounds, German DM and Japanese yen.

Panel A of Table 1 reports the summary statistics for log index returns computed in US dollars in excess of returns on the Eurodollar rate. The summary statistics include means, standard deviations, skewness, kurtosis, Bera-Jarque (1982) statistics, and the sample correlation. The magnitudes of the means, volatilities and correlations are very similar to those previously documented in other studies. The kurtosis values indicate that the unconditional distribution of excess log returns has heavier tails than the normal distribution for all countries. Furthermore, the Bera-Jarque statistics also show that the hypothesis of normality is rejected in our sample. Hence, we incorporate the heteroskedastic property when we estimate the asset pricing model.

Descriptive statistics for the state variables are reported in panel B of Table 1. We select a set of state variables that have been widely used in the literature. These instruments include the logarithm of the monthly MSCI world dividend yield (DIV) and the one-month US T-bill rate (TB) both in excess of the monthly Eurodollar rate. These variables have been found to measure the information that investors use to set prices in the market. For example, Campbell (1996) finds that the dividend yield has some predictive power for future stock returns. Similarly, Fama and Schwert (1977), Ferson (1989), and Ferson and Harvey (1991) find that the short-term T-bill rate (TB) is capable of predicting monthly returns of stocks and bonds. 
Table 1

Summary statistics of excess log returns

Panel A reports summary statistics for monthly dollar denominated log returns for four countries and the market portfolio. Panel B reports summary statistics for instrumental variables (in percentages per month) including the 30-day US T-bill returns (TB), and the logarithm of the monthly MSCI world dividend yield (DIV). All returns are in excess of returns on the monthly Eurodollar rate. The sample period is from January 1980 through December 1997.

Panel A: Excess returns

\begin{tabular}{lcccccc}
\hline & Weights $_{a}$ & Mean(*100) & SD(*100) & Skewness & Kurtosis & B-J \\
\hline USA & 0.35 & 0.3283 & 4.3762 & $-1.0290^{* *}$ & $5.0485^{* *}$ & $266.2657^{* *}$ \\
UK & 0.11 & 0.2540 & 5.8702 & $-0.4888^{*}$ & $1.9517^{* *}$ & $42.6871^{* *}$ \\
Germany & 0.04 & 0.1934 & 6.1322 & $-0.4682^{*}$ & $1.3120^{*}$ & $23.2785^{* *}$ \\
Japan & 0.31 & 0.1374 & 7.0080 & 0.0385 & $0.3476^{*}$ & $1.1354^{*}$ \\
World & 1 & 0.2255 & 4.2165 & $-0.7831^{*}$ & $2.4313^{* *}$ & $74.9264^{* *}$ \\
\hline
\end{tabular}

$*, * *$ denote statistical significant at the $5,1 \%$ level, respectively.

${ }^{a}$ as of 31 December 1990.

Panel B: Instrumental variables

\begin{tabular}{lrrrr}
\hline & Mean $(* 100)$ & $\mathrm{SD}(* 100)$ & Maximum & Minimum \\
\hline World $(-1)$ & 0.2173 & 4.2076 & 10.5096 & -20.1767 \\
$£(-1)$ & 0.0518 & 3.4764 & 14.2591 & -12.6903 \\
DM(-1) & -0.1401 & 3.5097 & 7.8664 & -10.8948 \\
Y(-1) & 0.0462 & 3.5450 & 10.9511 & -11.0821 \\
TB & -0.1078 & 0.0901 & 0.0441 & -0.3916 \\
DIV & -90.0291 & 31.0668 & -4.2420 & -146.9676 \\
\hline
\end{tabular}

We first construct the dynamic behaviour of state variables. Table 2 reports the estimates of the coefficients in the one-lag VAR. The first row of Table 2 reports the monthly forecasting equation for the excess log return of the market portfolio (World). Since there is little serial correlation in the monthly market log return, the coefficient for the World $(-1)$ is small and insignificant. However, the coefficient for world dividend yield (DIV) is significantly positive and the short-term T-bill rate (TB) is negative. The second row of Table 2 gives the monthly forecasting equation for the return on the currency deposit, $£$. The coefficient of lagged currency deposit returns is also small and insignificant. The remaining rows of Table 2 report the dynamics of the state variables. It can be seen that DIV behaves like a persistent AR(1) process with a coefficient of 0.9928 .

As discussed in Section 2, the intertemporal model applied to international financial markets implies that the conditional expected log return on any asset is linearly related to the covariance of asset return with market return, the covariance with news about the discounted value of all future market returns i.e. the hedging portfolio return, the covariance with the currency deposit return, and the covariance with news about the discounted value of all future currency deposit returns i.e. the currency hedging portfolio return. If the market risk, news about the discounted value of all future market risk, exchange rate risk, and news about the discounted value of all future exchange rate risk are the only four relevant factors, the price of covariance 
Table 2

VAR summary: dynamics of risk factor

We adopt the Vector Auto-Regressive (VAR) approach from Campbell (1991). We assume that the real market index return and currency portfolio return are the first and second elements of the state variable vector $\mathbf{z}_{\mathbf{t}}$. The other elements of $\mathbf{z}_{\mathbf{t}}$ are variables that are known to the market at the end of the period $t$ and are related to forecasting future market returns. In addition, we assume that the vector $\mathbf{z}_{\mathbf{t}}$ follows a first order VAR

\begin{tabular}{lccccccc}
\hline $\begin{array}{l}\text { Dependent } \\
\text { regressors } \\
\text { variables }\end{array}$ & World $(-1)$ & $£(-1)$ & $\mathrm{DM}(-1)$ & $\mathrm{Y}(-1)$ & $\mathrm{TB}(-1)$ & $\mathrm{DIV}(-1)$ & $R^{2}$ \\
\hline World & 0.0088 & -0.1758 & 0.1488 & 0.1207 & -1.4335 & 0.0100 & 0.0234 \\
& $(0.0740)$ & $(0.1198)$ & $(0.1288)$ & $(0.1099)$ & $(3.6347)$ & $(0.0053)$ & \\
$£$ & -0.0730 & 0.1345 & -0.0352 & 0.0034 & 3.2940 & -0.0045 & 0.0216 \\
& $(0.0612)$ & $(0.0990)$ & $(0.1064)$ & $(0.0908)$ & $(3.0035)$ & $(0.0044)$ & \\
DM & -0.1467 & 0.0439 & 0.0475 & 0.0178 & 3.0623 & -0.0015 & 0.0374 \\
& $(0.0613)$ & $(0.0993)$ & $(0.1067)$ & $(0.0911)$ & $(3.0114)$ & $(0.0044)$ & \\
Y & -0.0030 & -0.0347 & 0.0951 & 0.0599 & -1.4571 & 0.0029 & 0.0166 \\
& $(0.0626)$ & $(0.1013)$ & $(0.1088)$ & $(0.0929)$ & $(3.0719)$ & $(0.0045)$ & \\
TB & 0.0011 & -0.0018 & 0.0023 & -0.0018 & 0.7481 & 0.0002 & 0.8584 \\
& $(0.0009)$ & $(0.0015)$ & $(0.0016)$ & $(0.0013)$ & $(0.0460)$ & $(0.0001)$ & \\
DIV & -0.2714 & 0.1034 & 0.1212 & -0.1537 & -13.6528 & 0.9928 & 0.9924 \\
& $(0.1469)$ & $(0.2378)$ & $(0.2556)$ & $(0.2181)$ & $(7.2113)$ & $(0.0106)$ & \\
\hline
\end{tabular}

Standard errors are in parentheses.

risk $\gamma$ should be significantly positive and significantly greater or less than one. It should also be noted that the value of $\gamma$ should not be equal to zero or one.

In order to avoid the measurement error, the econometric system employed simultaneously estimates the parameters of VAR and the asset pricing model. The results are reported in Table 3. Consider the estimates of parameters in the VAR. All the elements in the parameter matrix are similar to the unconstrained estimates that are reported in Table 2. The estimate of $\gamma$ is 3.0884 which is significantly different from zero. This implies that the conditional expected international asset return varies with market volatility. This evidence supports the conditional version of the international CAPM. This result is the same as Chan et al. (1992). Next, consider the estimates of parameters in the multivariate GARCH process. All elements of vectors $\alpha$ and $\beta$ are statistically significant at any conventional level. Moreover, the estimates satisfy the stationary conditions, $\alpha_{i} \alpha_{j}+\beta_{i} \beta_{j}<1 \forall i$, $j$, for all the variance and covariance processes.

If the estimate of $\gamma$ is equal to one, the model collapses to the conditional CAPM. Since we have the unrestricted estimates, a Wald test would be a convenient way to proceed. The value of the criterion function is $\chi^{2}(1)=21.935$, which corresponds to a p-value of 0.000 . This implies that we can reject the hypothesis that market hedging demand, exchange rate risk, and currency hedging demand are not important factors in pricing international stock returns. In other words, the conditional expected international asset return varies with market volatility, market hedging volatility, 
Table 3

Quasi maximum likelihood estimates (QMLE) of international asset pricing

This table reports the estimates of the multivariate $\operatorname{GARCH}(1,1)$ Model, combining vector auto-regression and monthly excess $\log$ returns to four equity markets. Each mean equation is written as

$$
\begin{aligned}
& {\left[\begin{array}{c}
z_{t} \\
r_{t}-r_{f, t} \cdot i
\end{array}\right]=\left[\begin{array}{l}
\Phi z_{t-1} \\
-\frac{1}{2} h_{d, t}+\gamma h_{m, t}+(\gamma-1) h_{h, t}+(1-\gamma) h_{e, t}+(1-\gamma) h_{e h, t}
\end{array}\right]+\left[\begin{array}{l}
u_{t} \\
\xi_{t}
\end{array}\right]} \\
& \varepsilon_{t}=\left[\begin{array}{l}
u_{t} \\
\xi_{t}
\end{array}\right] \mid I_{t-1} \sim N\left(0, H_{t}\right),
\end{aligned}
$$

where $\gamma$ denotes the price of the market covariance or coefficient of relative risk aversion. The conditional covariance matrix is formulated as

$$
H_{t}=H_{0} *\left(i i^{\prime}-\alpha \alpha^{\prime}-\beta \beta^{\prime}\right)+\alpha \alpha^{\prime} * \varepsilon_{t-1} \varepsilon_{t-1}^{\prime}+\beta \beta^{\prime} * H_{t-1}
$$

\begin{tabular}{|c|c|c|}
\hline & \multicolumn{2}{|c|}{$\begin{array}{c}3.0884 \\
(0.4459)\end{array}$} \\
\hline & $\alpha$ & $\beta$ \\
\hline$r_{m, t}-r_{f, t}$ & $\begin{array}{c}0.2102 \\
(0.0233)\end{array}$ & $\begin{array}{c}0.9602 \\
(0.0085)\end{array}$ \\
\hline$£$ & $\begin{array}{c}0.1674 \\
(0.0307)\end{array}$ & $\begin{array}{c}0.9755 \\
(0.0147)\end{array}$ \\
\hline DM & $\begin{array}{c}0.1936 \\
(0.0432)\end{array}$ & $\begin{array}{c}0.9507 \\
(0.0208)\end{array}$ \\
\hline $\mathrm{Y}$ & $\begin{array}{c}0.1902 \\
(0.0233)\end{array}$ & $\begin{array}{c}0.9677 \\
(0.0083)\end{array}$ \\
\hline TB & $\begin{array}{c}0.2100 \\
(0.0200)\end{array}$ & $\begin{array}{c}0.9605 \\
(0.0076)\end{array}$ \\
\hline DIV & $\begin{array}{c}0.1753 \\
(0.0410)\end{array}$ & $\begin{array}{c}0.9512 \\
(0.0267)\end{array}$ \\
\hline USA & $\begin{array}{c}0.2138 \\
(0.0475)\end{array}$ & $\begin{array}{c}0.9250 \\
(0.0331)\end{array}$ \\
\hline UK & $\begin{array}{c}0.1561 \\
(0.0197)\end{array}$ & $\begin{array}{c}0.9805 \\
(0.0093)\end{array}$ \\
\hline Germany & $\begin{array}{c}0.3063 \\
(0.0270)\end{array}$ & $\begin{array}{c}0.9484 \\
(0.0098)\end{array}$ \\
\hline Japan & $\begin{array}{c}0.3054 \\
(0.0286)\end{array}$ & $\begin{array}{c}0.9506 \\
(0.0096)\end{array}$ \\
\hline
\end{tabular}

where $\alpha$ and $\beta$ are a $10 \times 1$ vector of constant.

Parameter estimates

currency volatility and currency hedging volatility simultaneously. This evidence supports the international version of the intertemporal asset pricing model.

The price of risk that arises from the traditional covariance of an asset's return with market return is $\gamma+(\gamma-1) \theta_{h 1}+(1-\gamma) \sum_{l=1}^{L} \theta_{e 1}^{l}$, where $\theta_{h 1}$ is the first element of $\theta_{h}$ and 
$\theta_{e 1}^{l}$ is the first element of $\theta_{e}$. Therefore, this model provides a distinct link between the coefficient of relative risk aversion, $\gamma$, and the various prices of risks.

\section{Disentangling exchange rate risk from intertemporal hedging risk}

In the last section, we use an econometric method to examine whether or not relative risk aversion, $\gamma$, is different from one. The result shows that three risk components, which depend on whether or not the value for relative risk aversion, $\gamma$, is different from one, all significantly explain the cross-section of equity returns in the USA, UK, Germany and Japan. However, we would like to know their relative importance. Table 4 reports the mean of the risk variables for the US, UK, Germany, and Japan equity markets. The traditional international CAPM uses only the market risk and exchange rate risk to price assets, whereas the intertemporal model also compensates for market hedging risk and exchange rate hedging risk. Table 4 shows some striking results about the risk characteristics of international equity returns. First, we compare the market risk premium and the exchange rate risk premium for our equity markets. For the US equity market, the market risk is very important for explaining return whereas the exchange rate risk is small and not significant. In the other three equity markets, we find that although exchange rate risk is less important than market risk, it is still an important factor to explain equity market return.

Table 4

Summary of risk premiums

This table reports the annualised means and standard deviations for the risk premiums. The total premium (TP) is the sum of the market premium (MP), the market hedging premium (MHP), the currency premium $(\mathrm{CP})$ and currency hedging premium (CHP). The definition of risk premium is as follows.

$$
\begin{aligned}
T P= & \gamma \operatorname{cov}\left(r_{i, t}, r_{m, t}\right)+(\gamma-1) \operatorname{cov}\left(r_{i, t}, r_{h, t}\right)+(1-\gamma) \sum_{l} \omega^{l} \operatorname{cov}\left(r_{i, t}, r_{e, t}^{l}\right) \\
& +(1-\gamma) \sum_{l} \omega^{l} \operatorname{cov}\left(r_{i, t}, r_{e h, t}^{l}\right) \\
& M P=\gamma \operatorname{cov}\left(r_{i, t}, r_{m, t}\right) \quad M H P=(\gamma-1) \operatorname{cov}\left(r_{i, t}, r_{h, t}\right) \\
& C P=(1-\gamma) \sum_{l} \omega^{l} \operatorname{cov}\left(r_{i, t}, r_{e, t}^{l}\right) \quad C H P=(1-\gamma) \sum_{l} \omega^{l} \operatorname{cov}\left(r_{i, t}, r_{e h, t}^{l}\right)
\end{aligned}
$$

\begin{tabular}{lccrrr}
\hline & TP & MP & MHP & CP & CHP \\
\hline USA & & & & & \\
Mean & 4.3681 & 5.4035 & -1.3546 & 0.0579 & 0.2610 \\
SD & 1.0023 & 1.7551 & 1.3885 & 0.2067 & 0.2118 \\
UK & & & & & \\
Mean & 5.1384 & 6.9687 & -1.2515 & -0.7548 & 0.1760 \\
SD & 1.1164 & 1.7529 & 1.3188 & 0.2218 & 0.2401 \\
Germany & & & & & \\
Mean & 4.3776 & 5.6133 & -0.2906 & -0.9761 & 0.0316 \\
SD & 1.3628 & 1.7056 & 1.4192 & 0.2919 & 0.2468 \\
Japan & & & & & \\
Mean & 6.7094 & 8.0265 & -0.7827 & -0.9013 & 0.3688 \\
SD & 1.7167 & 2.2407 & 1.5124 & 0.2163 & 0.2773 \\
\hline
\end{tabular}


These findings are consistent with Dumas and Solnik (1995) and De Santis and Gerard (1998) who also find that exchange rate risk is important for pricing international equity returns.

Second, Dumas and Solnik (1995) claim that exchange rate risk might be proxying for market hedging risk. Table 4 also allows a comparison of the magnitudes between market hedging risk premium and exchange rate risk premium. Except for the US equity market, the exchange rate risk premia are highly significant relative to market hedging risk premia. This might be because we use the US dollar as a currency measure, so exchange rate risk become less important for the US equity market. Hence, we can conclude that if PPP is violated, exchange rate risk is a more important factor than hedging risk in the international asset pricing model. This implies that the conclusion of Chang and Hung (2000) and Hodrick et al. (2000) which states that hedging risk is important in the international asset pricing model should be reassessed in the presence of exchange rate risk.

Third, DeSantis and Gerard (1998) explain the negative exchange rate risk since one would be willing to give up larger expected returns for smaller expected returns because currency can provide a hedge to PPP deviation. However, this is a relationship of contemporary hedge. Table 4 shows that market risk premium is positive, market hedging risk premium is negative, exchange rate risk premium is negative except for the USA, and exchange rate hedging risk is positive. In addition to contemporary hedge between exchange rate risk premium and market risk premium, market hedging risk premium and exchange rate hedging risk premium are two intertemporal hedges to market risk premium and exchange rate risk premium. That is because future market and future currency returns can provide a hedge to market and currency returns.

In order to examine the difference between market hedging risk and exchange rate risk over our sample period, we plot the two risks in Figures 1-4. We observe large increases in market hedging risk associated with the big market drops of 1987 and 1990. However, the scale of market hedging risk is smaller than that of market risk. That is because we separate exchange rate risk and exchange rate hedging risk from the market hedging risk, and hence the components of exchange rate risk and exchange rate hedging risk absorb some information from market hedging risk. In addition, the pattern of market hedging risk is different from the pattern of exchange rate risk in all equity markets. Sometimes, we find that market hedging risk and exchange rate risk are in a negative relationship, whereas at other times they show a positive relationship. Dumas and Solnik (1995) denote that exchange rates can serve as proxies for state variables when constructing intertemporal risk premia, however in our theoretical model we can separate the exchange rate risk and intertemporal risk into two different risks. Thus, the conclusion of Dumas and Solnik (1995) that exchange rate risk may be equivalent to intertemporal risk needs to be reevaluated.

\section{Conclusions}

This paper develops an intertemporal IAPM. We use a loglinear approximation of the budget constraint to obtain an international asset pricing model without consumption. The model shows that the expected asset return is determined by a weighted average of market risk, market hedging risk, exchange rate risk, and exchange rate hedging risk. The weights are related only to relative risk aversion and sum up to one. 


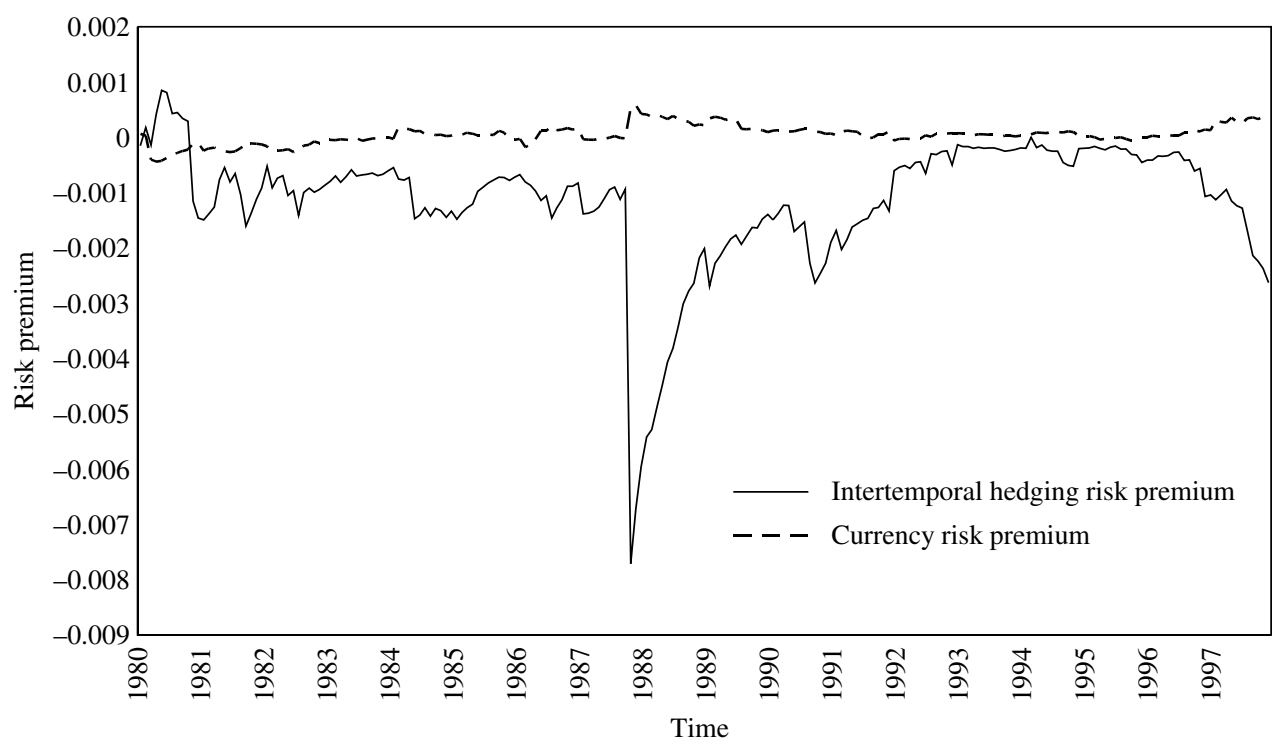

Fig. 1. Risk premiums: US equity

Our model can be viewed as a special case of the pioneering work of Stulz (1981). Our results can be contrasted with the work of Adler and Dumas (1983) who assumed a constant investment opportunity set, and did not deal with market hedging risk and exchange rate hedging risk. We are able to explicitly separate hedging against changes in the investment opportunity set from hedging against exchange rate changes as well as separate exchange rate risk from intertemporal hedging risk. In our model, the price of market hedging risk is equal to the negative price of exchange rate risk. This could be the reason why Dumas and Solnik (1995) argue that exchange rate risk is

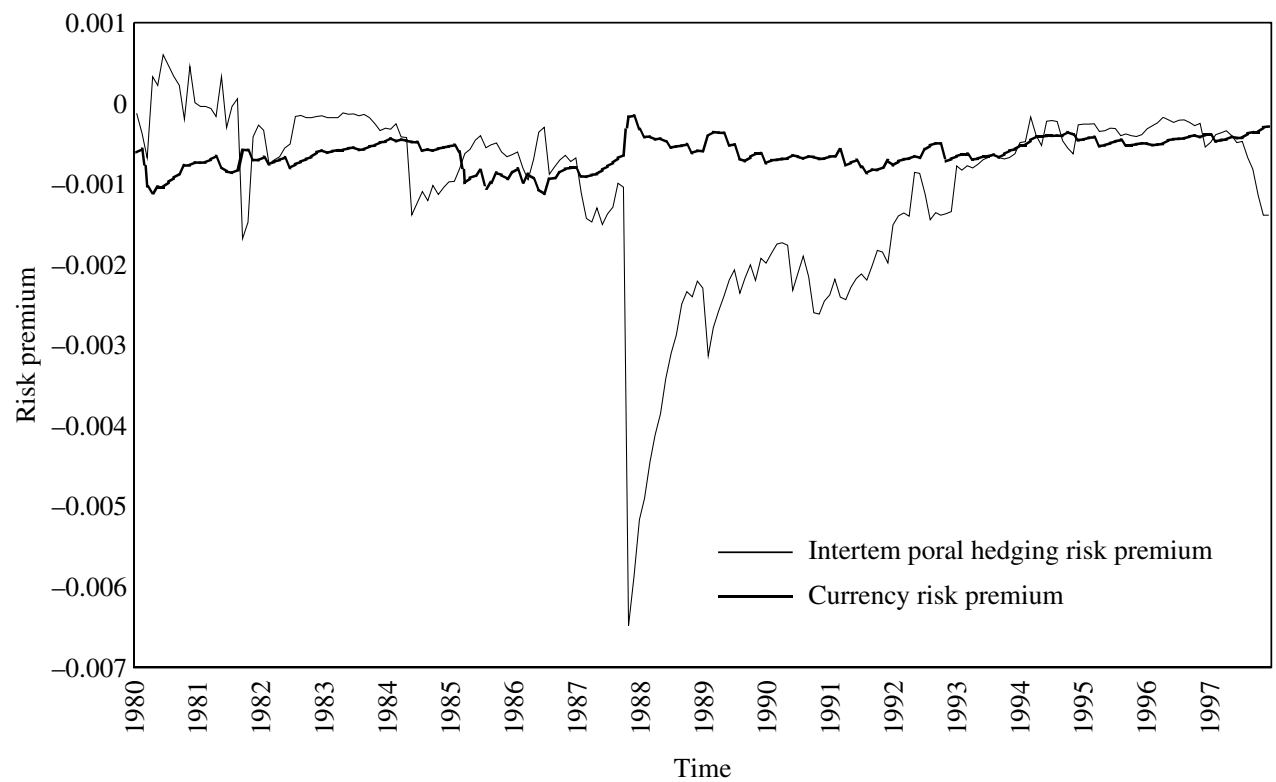

Fig. 2. Risk premiums: UK equity 


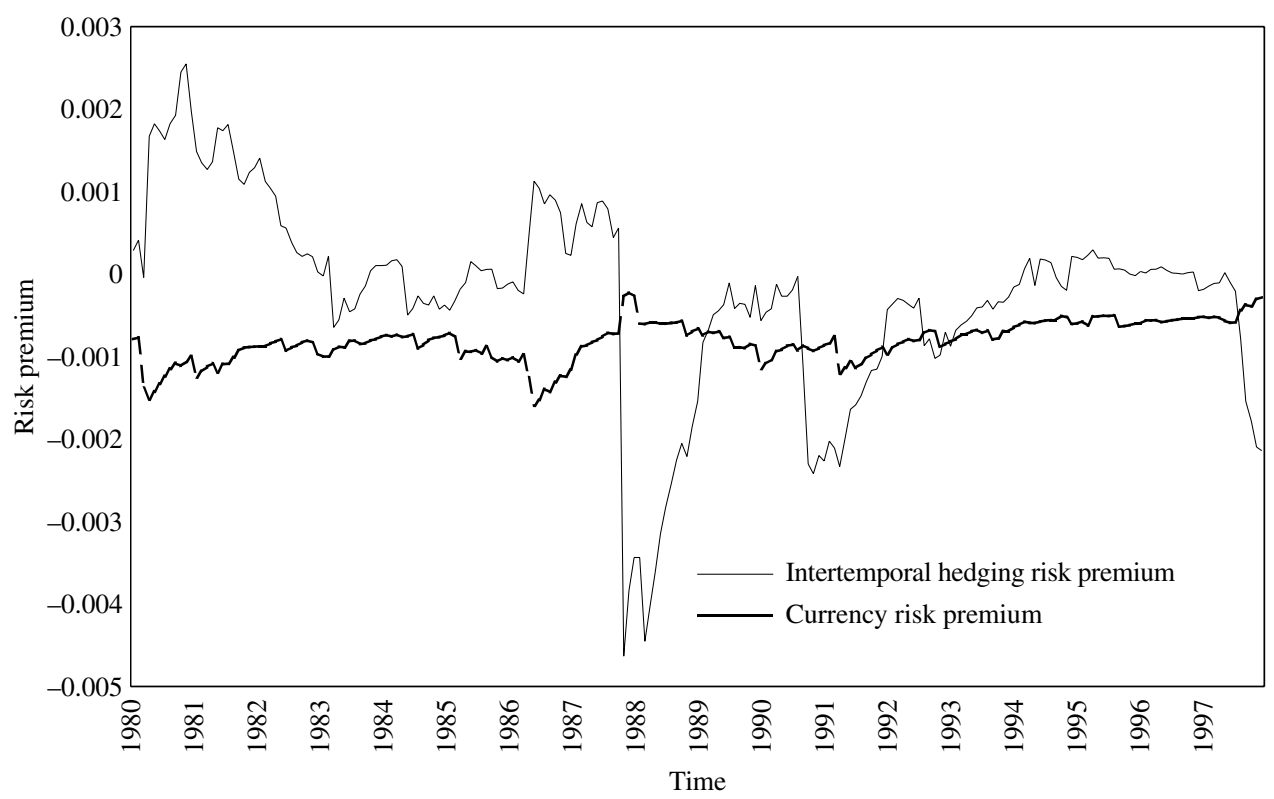

Fig. 3. Risk premiums: Germany equity

equivalent to market hedging risk. However, their conjecture is based on a 'horse race' test between the international model and the intertemporal model.

Empirically, we investigate our dynamic international asset pricing model for the US, UK, Germany and Japan equity markets. Our international model is a fourfactor model in which assets are priced using their covariance not only with the market portfolio and the currency deposit return, but also with the market hedging

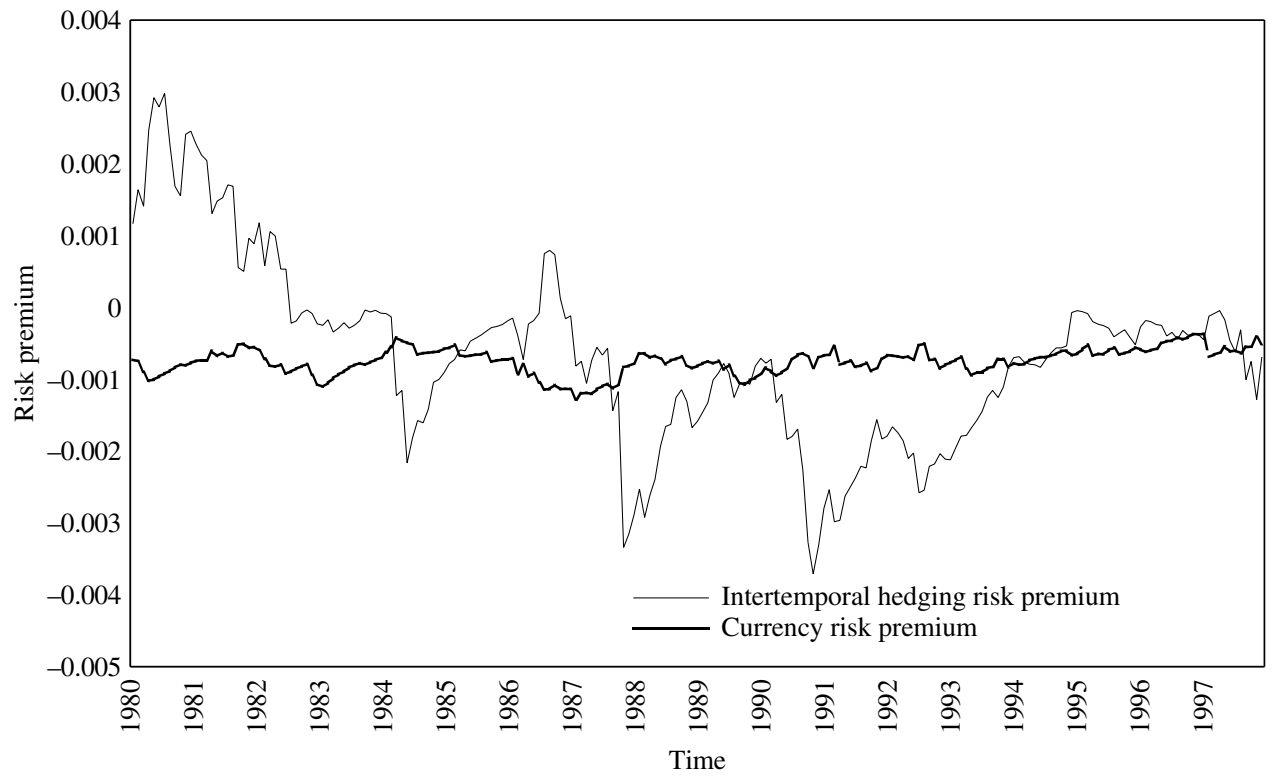

Fig. 4. Risk premiums: Japanese equity 
portfolio and the currency hedging portfolio that account for changes in the investment set. The evidence supports the hypothesis that the market risk is important in an international setting. Furthermore, we can reject the hypothesis that market hedging demand, exchange rate risk, and currency hedging demand are not important factors in pricing international stock returns. Thus, the evidence supports the international version of the intertemporal asset pricing model. Finally, we show that the exchange rate risk is different from market hedging risk and the relationship between exchange rate risk and market hedging risk may be positive or negative. This suggests that exchange rate risk and market hedging risk are two different risks in international asset pricing with the exchange rate risk being much more important than market hedging risk.

This paper links the intertemporal asset pricing model of Campbell (1993) and international asset pricing model of Adler and Dumas (1983) to construct an international intertemporal asset pricing model. The theoretical model shows that the expected international asset return is determined by a weighted average of market risk, market hedging risk, exchange rate risk and exchange rate hedging risk. In the empirical literature, DeSantis and Gerard (1998) show that currency risk is an important factor of risk premium. Dumas and Solnik (1995) show that both intertemporal model and international model can explain the risk premium. In this paper, we propose a unified model of intertemporal risk and currency risk. The results show that international intertemporal model can not be rejected by our international data. Past empirical tests of international data have relied upon conditional versions of the static IAPMs. Indeed, a conditional test of an IAPM should be based on an intertemporal model. Our IAPM fills this gap.

\section{References}

Adler, M. and Dumas, B., 'International portfolio selection and corporation finance: a synthesis,' Journal of Finance, Vol. 38, 1983, pp. 925-984.

Bansal, R. D. Hsieh, H, and Viswanathan, S., 'A new approach to international arbitrage pricing,' Journal of Finance, Vol. 48, 1993, pp. 1719-1747.

Bera, A. K. and Jarque, C. M., 'Model specification tests: a simultaneous approach,' Journal of Econometrics, Vol. 20, 1982, pp. 59-82.

Bollerslev, T. and Wooldridge, J. M. 'Quasi-maximum likelihood estimation and inference in dynamic models with time-varying covariances,' Econometrics Reviews, Vol. 11, 1992, pp. 143-172.

Campbell, J. Y., 'A variance decomposition for stock returns,' Economic Journal, Vol. 101, 1991, pp. 157-179.

Campbell, J. Y., 'Intertemporal asset pricing without consumption data,' American Economic Review, Vol. 83, 1993, pp. 487-512.

Campbell, J. Y., 'Understanding risk and return,' Journal of Political Economy, Vol. 104, 1996, pp. 298-345.

Carrieri, F., 'The effects of liberalization on market and currency risk in the European Union,' European Financial Management, Vol. 7, 2001, pp. 259-290.

Chan, K. C., Karolyi, G. A. and Stulz, R. M., 'Global financial markets and the risk premium on US equity,' Journal of Financial Economics, Vol. 32, 1992, pp. 137-167.

Chang, J. R. and Hung, M. W., 'An international asset pricing model with time-varying hedging risk,' Review of Quantitative Finance and Accounting, Vol. 15, 2000, pp. 235-257.

Cumby, R. E., 'Consumption risk and international equity returns: Some empirical evidence,' Journal of international Money and Finance, Vol. 9, 1990, pp. 182-192.

De Santis, G. and Gerard, B., 'International asset pricing and portfolio diversification with time-varying risk,' Journal of Finance, Vol. 52, 1997, pp. 1881-1912.

(C) Blackwell Publishing Ltd, 2005 
De Santis, G. and Gerard, B., 'How big is the premium for currency risk?' Journal of Financial Economics, Vol. 49, 1998, pp. 375-412.

Ding, Z. and Engle, R. F., 'Large scale conditional covariance matrix modeling, estimation and testing' Working Paper (University of California at San Diego, 1994.

Dumas, B. and Solnik, B., 'The world price of foreign exchange rate risk,' Journal of Finance, Vol. 50, 1995, pp. 445-479.

Epstein, L. G. and Zin, S. E., 'Substitution, risk aversion, and the temporal behavior of consumption and asset returns: a theoretical framework,' Econometrica, Vol. 57, 1989, pp. 937-969.

Epstein, L. G. and Zin, S. E., 'Substitution, risk aversion, and the temporal behavior of consumption and asset returns: an empirical analysis,' Journal of Political Economy, Vol. 99, 1991, pp. 263-286.

Fama, E. F. and Schwert, G. W., 'Asset returns and inflation,' Journal of Financial Economic, Vol. 5, 1977, pp. 115-1461.

Ferson, W., 'Changes in expected security returns, risk, and the level of interest rates,' Journal of Finance, Vol. 44, 1989, pp. 1191-1217.

Ferson, W. and Harvey, C. R., 'Variation of economic risk premiums,' Journal of Political Economy, Vol. 99, 1991, pp. 385-415.

Ferson, W. and Harvey, C. R., 'The risk and predictability of international equity returns,' Review of Financial Studies, Vol. 6, 1993, pp. 527-567.

Giovannini, A. and Weil, P., 'Risk aversion and intertemporal substitution in the capital asset pricing model,' (NBER, 2824, 1989).

Harvey, C. R., 'The world price of covariance risk,' Journal of Finance, Vol. 46, 1991, pp. 111-157.

Hodrick, R. J., Ng, D. and Sengmueller, P., 'An international dynamic asset pricing model,' International Tax and Public Finance, Vol. 6, no. 4, 2000, pp. 597-620.

Kreps, D. and Porteus, E., 'Temporal resolution of uncertainty and dynamic choice theory,' Econometrica, Vol. 46, 1978, pp. 185-200.

Korajczyk, R. and Viallet, C., 'An empirical investigation of international asset pricing,' Review of Financial Studies, Vol. 2, 1989, pp. 553-585.

Merton, R. C., 'An intertemporal capital asset pricing model,' Econometrica, Vol. 41, 1973, pp. $867-887$.

Narayana, K., 'Disentangling the coefficient of relative risk aversion from the elasticity of intertemporal substitution: an irrelevance result,' Journal of Finance, Vol. 45, 1990, pp. $175-190$.

O'Brien, T. and Dolde, W., 'A currency index global capital asset pricing model,' European Financial Management, Vol. 6, 2000, pp. 7-18.

Restoy, F., 'Optimal portfolio policies under time-dependent returns,' unpublished manuscript (Harvard University, 1991).

Ross, S. A., 'The arbitrage theory of capital asset pricing,' Journal of Economic Theory, Vol. 13, 1976, pp. 341-360.

Solnik, B., 'The world price of foreign exchange risk: some synthetic comments,' European Financial Management, Vol. 3, 1997, pp. 9-22.

Solnik, R. E., 'An equilibrium model of the international capital market,' Journal of Economic Theory, Vol. 8, 1974, pp. 500-524.

Stulz, R. M., 'A model of international asset pricing,' Journal of Financial Economics, Vol. 9, 1981, pp. 383-406.

Stulz, R. M., 'Pricing capital assets in an international setting: an introduction,' Journal of International Business Studies, Winter 1984, pp. 55-73.

Svensson, L. E. O., 'Portfolio choice with non-expected utility in continuous time,' Economics Letters, Vol. 30, 1989, pp. 313-317.

Weil, P., 'The equity premium puzzle and the risk free rate puzzle,' Journal of Monetary Economic, Vol. 24, 1989, pp. 401-421. 